\title{
A study of disability profile and burden in caregivers of stable schizophrenia patients
}

\author{
Neha Modi ${ }^{1}$, Ritambhara Mehtaํ, Pradhyuman Chaudhary², Kamlesh Dave ${ }^{1}$ \\ ${ }^{1}$ Department of Psychiatry, Government Medical College, Surat, Gujarat, India \\ 2Department of Psychiatry, GMERS Medical College, Sola, Ahmedabad, Gujarat, India \\ Neuropsychiatria i Neuropsychologia 2020; 15, 3-4: 108-115
}

Address for correspondence:

Pradhyuman Chaudhary, MD

GMERS Medical College

Sola, Ahmedabad, Gujarat, India

phone: 919825411772

e-mail: drpradhyuman@gmail.com

\begin{abstract}
Introduction: Schizophrenia is one of the most devastating disorders, leading to long-term and progressive disability in numerous individuals. Disability reflects an interaction between features of a person's body and of the society. In all treatments, family psycho-education is also very important as disability of schizophrenia leads to burden upon family members. Caregiver burden can be either objective or subjective. Objective burdens are behavioural phenomena: disruption of the social activities and financial difficulties. Subjective burdens comprise emotional strain on caregivers. Due to the chronic nature of the disease and the disability, patients with schizophrenia as a group need most care in social and economic areas.

Aim of the study: To assess the level of burden in caregivers of stable schizophrenia patients and their relation with degree of disability in schizophrenia patients. It was a cross-sectional and observation study. Material and methods: The study was carried out with 154 stable patients of International Classification of Diseases diagnosed schizophrenia and their primary caregivers. The patients were evaluated on the Indian Disability Evaluation and Assessment Scale (IDEAS) and Positive and Negative Syndrome Scale (PANSS), and the Burden Assessment Schedule (BAS) was used for their primary caregiver.

Results: Two thirds of schizophrenia patients who were stable on medication for at least 6 months and diagnosed with schizophrenia for at least 2 years had mild (70.12\%) and the rest had moderate disability (29.87\%). Greater burden of care was experienced with increasing age.

Conclusions: Caregivers' burden has a direct correlation with overall disability. Deficiency in interaction, communication and employment leads to more burden of care, but not a deficiency in self-care.
\end{abstract}

Key words: schizophrenia, disability, caregiver burden.

\section{Introduction}

Among various psychiatric disorders, schizophrenia is one of the most devastating, leading to long-term and progressive disability in numerous individuals (Kung 2003; Martyns-Yellowe 1992). Schizophrenia is characterized by disordered cognition, including a "gain of-function" in psychotic symptoms and a "loss of-function" in specific cognitive functions, such as working and declarative memory (Tamminga 2009).

It is a chronic, disabling psychiatric illness with marked heterogeneity with respect to symptoms, onset, course, prognosis, treatment responsiveness, and outcome. It is characterized by a fluctuating course of illness with intermittent periods of acute psychosis and remission, often with residual symptoms during remission.
Heterogeneity means that the experience of schizophrenia varies considerably from person to person and from family to family. Estimates of lifetime prevalence range from $0.6 \%$ to $1.9 \%$ (Tamminga 2009).

In the past three decades, the concept of disability has shifted from individual impairment to a more social phenomenon. Disability is a complex phenomenon, reflecting an interaction between features of a person's body and features of the society in which he or she lives (Chandrashekar et al. 2010).

Treatment of schizophrenia includes pharmacological such as anti-psychotic drugs and non-pharmacological such as training in social skills and problem-solving, supportive therapy, interpersonal therapy, cognitive therapy, vocational rehabilitation, and psychosocial rehabilita- 
tion. Above all, family psycho-education is also very important as disability of schizophrenia leads to a burden upon family members (Tamminga 2009).

The World Health Organization (WHO) states caregiver burden as the "the emotional, physical, financial demands and responsibilities of an individual's illness that are placed on the family members, friends or other individuals involved with the individual outside the health care system".

Caregiver burden can be either objective or subjective. Objective burdens are defined as readily verifiable behavioural phenomena, e.g. negative patient symptoms; disruption of the caregiver's domestic routine social activities and leisure; social isolation; and financial and employment difficulties (Kuipers 1993; Greenberg et al. 1993). Subjective burdens comprise emotional strain on caregivers, e.g. frustration, depression, fear, sadness, anger, guilt, loss, stigma and rejection (Greenberg et al. 1993; Tsang et al. 2003). Previous research exploring the caregiver experience in the broader schizophrenia population has demonstrated considerable objective and subjective burdens of providing informal care of patients (Flyckt et al. 2013; Vermeulen et al. 2015; Ong et al. 2016; Caqueo-Urízar et al. 2009).

Due to the chronic nature of the disease and the disability it causes, patients with schizophrenia are among the patient groups that need care most in social and economic areas (Cloutier $e t a l$. 2016; Marcellusi et al. 2018; Chang et al. 2008).

In summary, the aim of this study was to assess the disability profile in stable patients and level of burden in caregivers of these patients with schizophrenia. The study will help determine the degree of disability in this stable outpatient population with regular follow-up and low active psychopathology, which may later on be used for disability certification and policy.

\section{Material and methods}

\section{Study setting and population}

This cross-sectional study was conducted at the department of psychiatry of a tertiary care centre from south Gujarat.

The study population included patients with schizophrenia diagnosed using International Classification of Disease-10 (World Health Organization, 1992). The inclusion criteria for patients were age between 16 and 60 years, minimal duration of illness of 2 years, patients with regular follow-up for at least 6 months and stable on medication without major changes in the last 6 months, with a Positive and Negative Syndrome Scale (PANSS) score $<75$ and who gave valid informed consent.

The inclusion criteria for caregivers were those who live with a patient for at least 6 months or more with age of 18 years and above, with no previously diagnosed psychiatric illness.

A semi structured proforma was used to collect socio-demographic like age, sex, education, marital status etc. and illness details.

\section{Assessment tools}

\section{Burden Assessment Schedule \\ (Thara et al. 1998)}

The Burden Assessment Schedule (BAS) was developed at the Schizophrenia Research Foundation, India, to assess the burden among primary caregivers of chronic mentally ill persons.

This is a semi-quantitative, 40-item scale measuring 9 different areas of objective and subjective caregiver burden. Each item is rated on a 3-point scale - not at all, to some extent, and very much. It includes nine domains: 1 . Spouse related, 2. Physical and mental health of caregiver, 3. External support, 4. Caregiver routine, 5. Support of patients, 6. Taking responsibility, 7. Other relationship, 8. Patient's behaviour, 9. Caregiver's strategy. 1, 8, 11, 13, 15, 17, 18, $24,25,29,34,35,36,39,40$ items are reverse coded. Scores range from 40 to 120 with higher scores indicating greater burden, i.e. mild burden (0-40), moderate burden (41-80) and severe burden (81-120).

\section{Indian Disability Evaluation and Assessment Scale (Rehabilitation Committee of Indian Psychiatry Society 2002)}

The Indian Disability Evaluation and Assessment Scale (IDEAS) is a scale for measuring and quantifying disability in mental disorders and developed by the Rehabilitation Committee of the Indian Psychiatric Society. An IDEAS is a well-validated instrument and is used across the country for disability evaluation in psychiatric disorders.

It has good criterion validity and face validity. Criterion validity of the scale has been established by comparing IDEAS with WHODAS.

It assesses disability under four domains: selfcare, interpersonal activities (social relationships), communication and understanding, and work.

Scoring: 0 - no disability, 1-6 - mild, 7-13 - moderate, 14-19 - severe and 20 - profound disability. 


\section{Positive and Negative Syndrome Scale}

(Kay et al. 1987)

The Positive and Negative Syndrome Scale measures symptom severity of patients with schizophrenia. It was published in 1987 by Stanley Kay, Lewis Opler, and Abraham Fiszbein. Each of the 30 items is accompanied by a specific definition as well as detailed anchoring criteria for all seven rating points. Scoring: There are 7 items each in the positive and negative scale and 16 items in the General Psychopathology Scale. Each item is rated on a severity scale from 1 to 7 . For the positive scale and negative scale, the total score ranges from 7 to 49 and the General Psychopathology Scale ranges from 16 to 112. A higher score denotes greater severity on each scale.

The cross-sectional observational study was approved by the institutional Ethics Committee. All the diagnosed clinically stable schizophrenia patients and their caregiver who came in to the general hospital psychiatric units (GHPU), who fulfilled all inclusion and exclusion criteria and gave informed valid consent after understanding the Participant Information Sheet, were included in this study.

154 patients with schizophrenia of at least 2 years' duration and 6 months' stability on the same antipsychotic medication were included. Socio-demographical profile, IDEAS, and PANSS were administered to the patients and BAS was administered to their caregivers.

\section{DATA analysis}

The results were subjected to statistical analysis with SPSS trial version 20.0 using the $t$ test and $\chi^{2}$ test.

\section{Results}

Table 1 shows the profile of various demographic and psychosocial details of the patients and their caregivers. Patients had a mean age of $38.86( \pm 8.9)$ years with the range of 16 to 60 years of age and caregivers had a mean age of $45.12( \pm 12.3)$ years with the range of 21 to 65 or more years of age.

Table 1. Demographic and psychosocial profile of patients and caregivers of patients with schizophrenia $(n=154)$

\begin{tabular}{|c|c|c|c|c|c|}
\hline \multirow[t]{2}{*}{ Variables } & & \multicolumn{2}{|c|}{ Patients } & \multicolumn{2}{|c|}{ Caregivers } \\
\hline & & Frequency $(n)$ & $\%$ & Frequency $(n)$ & $\%$ \\
\hline \multirow[t]{2}{*}{ Sex } & male & 87 & 56.5 & 94 & 61.0 \\
\hline & female & 67 & 43.5 & 60 & 39.0 \\
\hline \multirow[t]{2}{*}{ Education } & illiterate & 127 & 82.47 & 126 & 81.81 \\
\hline & literate & 29 & 17.53 & 30 & 18.19 \\
\hline \multirow[t]{3}{*}{ Occupation } & unemployed & 23 & 14.9 & 14 & 9.1 \\
\hline & employment & 79 & 51.3 & 94 & 61.0 \\
\hline & housework & 52 & 33.8 & 46 & 29.9 \\
\hline For patients & & \multicolumn{2}{|c|}{ Frequency $(n)$} & \multicolumn{2}{|c|}{$\%$} \\
\hline \multirow{5}{*}{$\begin{array}{l}\text { Socioeconomic } \\
\text { class }\end{array}$} & upper & \multicolumn{2}{|c|}{5} & \multicolumn{2}{|c|}{3.2} \\
\hline & upper middle & \multicolumn{2}{|c|}{12} & \multicolumn{2}{|c|}{7.79} \\
\hline & middle lower & \multicolumn{2}{|c|}{32} & \multicolumn{2}{|c|}{20.74} \\
\hline & upper lower & \multicolumn{2}{|c|}{88} & \multicolumn{2}{|c|}{57.14} \\
\hline & lower & \multicolumn{2}{|c|}{15} & \multicolumn{2}{|c|}{9.7} \\
\hline \multirow[t]{6}{*}{ Marital status } & married & \multicolumn{2}{|c|}{106} & \multicolumn{2}{|c|}{68.8} \\
\hline & unmarried & \multicolumn{2}{|c|}{26} & \multicolumn{2}{|c|}{16.9} \\
\hline & separated & \multicolumn{2}{|c|}{4} & \multicolumn{2}{|c|}{2.6} \\
\hline & single & \multicolumn{2}{|c|}{12} & \multicolumn{2}{|c|}{7.8} \\
\hline & divorced & \multicolumn{2}{|c|}{5} & \multicolumn{2}{|c|}{3.2} \\
\hline & widow & \multicolumn{2}{|c|}{1} & \multicolumn{2}{|c|}{0.6} \\
\hline \multicolumn{6}{|l|}{ For caregivers } \\
\hline \multirow{3}{*}{$\begin{array}{l}\text { Relationship } \\
\text { of caregiver }\end{array}$} & spouse & & & & \\
\hline & other & & & & \\
\hline & total & & & & \\
\hline
\end{tabular}


Illness profile of patients with schizophrenia

As only improved and stable patients with a PANSS score $<75$ were included in the study, their positive symptoms score range was 7-16 with mean $7.6( \pm 1.5)$, negative symptom score range of 7-24 with mean $9.83( \pm 3.9)$, general score range of $16-33$ with mean $19.75( \pm 3.7)$ and supplementary score range $2-8$ with 2.31 ( \pm 0.6$)$ (Table 2).

\section{Disability profile of patients}

All had mild to moderate level disability (Table 3). In various domains of the IDEAS scale, 93\% $(n=14)$ had no deficiency, $6 \%(n=8)$ had mild and $1 \%(n=2)$ had moderate deficiency in the self-care domain, but no severe deficiency. $66 \%(n=103)$ of patients had no deficiency, $26 \%(n=41)$ had mild and 6\% $(n=10)$ had moderate deficiency in the interpersonal domain. $49 \%(n=76)$ of patients had no deficiency, $30 \%(n=47)$ had mild and 20\% $(n=31)$ had moderate deficiency in the communication domain. 38\% $(n=59)$ of patients had no deficiency, $37 \%(n=57)$ had mild, $14 \%(n=23)$ had moderate, $6 \%(n=10)$ had severe and $3 \%(n=5)$ had profound deficiency in the employment domain.

There is a positive correlation between age and IDEAS total score in these patients, which shows that patient's disability increases with increasing patient's age $(p=0.04)$. There is a positive correlation between occupation and IDEAS total score in these patients with the $p$ value of $<0.01$ being significant, which shows that patient's occupation had a large impact on patient's disability $(p<0.01)$. In occupation, unemployed patients had more disability than employed patients.

\section{Burden in caregivers}

Table 4 shows that $51.9 \%(n=80)$ of caregivers had lower burden and $48.50 \%(n=74)$ had higher burden on the BAS scale. In our study a BAS score above 65 was considered as higher burden.

Table 5 shows the mean caregiver burden on the various domains of the BAS scale (spouse $n=83$, other caregiver $n=71$ ).
Our study shows that there is significant correlation in spouse-related domain with sex and education, with the $p$ values 0.04 and 0.01 respectively being significant (Table 6). Caregivers of more than 50 years had more burden than other age groups. Burden of care increases with increasing age. Female spouse caregivers perceived more burden of care than male spouses. There is no correlation of occupation, family and spending time with the patient on burden of care in spouses, with the $p$ value being insignificant.

Association of caregiver burden (total BAS score) with demographic variables (spouse $n=83$, other caregiver $n=71$ ) was shown in Table 7.

In our study, the relation of different demographic variables with total BAS score shows that sex had an effect on burden of care associated with caregivers, with the $p$ value (0.03) being statistically significant. Burden of care increases with increasing age of caregivers and female caregivers perceived more burden than males. Others parameters - education, caregiver's and patient's occupation - had no correlation with total BAS score, as the $p$ value is not statistically significant $(>0.05)$. Caregivers in the age group of 36-45 years had a lesser burden than other age groups, while in our study, caregivers of the

Table 2. Illness profile of patients with schizophrenia $(N=154)$

\begin{tabular}{|c|c|c|c|}
\hline Variables & & Frequency $(n)$ & $\%$ \\
\hline \multirow{3}{*}{$\begin{array}{l}\text { Duration } \\
\text { of illness }\end{array}$} & $2-5$ years & 27 & 17.5 \\
\hline & $6-9$ years & 42 & 27.2 \\
\hline & $\geq 10$ years & 85 & 55.1 \\
\hline \multirow[t]{2}{*}{ Admission } & absent & 102 & 66.2 \\
\hline & present & 52 & 33.7 \\
\hline
\end{tabular}

Table 3. Disability profile of patients with schizophrenia $(n=154)$

\begin{tabular}{|c|c|c|c|c|}
\hline $\begin{array}{l}\text { IDEAS } \\
\text { Disability }\end{array}$ & $\begin{array}{c}\text { Male } \\
(n=87)\end{array}$ & $\begin{array}{l}\text { Female } \\
(n=67)\end{array}$ & $\begin{array}{c}\text { Pearson } \\
\chi^{2}\end{array}$ & $p$ value \\
\hline Mild & 58 & 46 & 0.68 & 0.79 \\
\hline Moderate & 29 & 21 & & \\
\hline
\end{tabular}

Table 4. Caregiver burden of patients with schizophrenia on burden assessment schedule scale

\begin{tabular}{llllllll} 
& Level of burden & $n$ & Range & Mean & SD & $t$ test & $p$ value \\
\multirow{2}{*}{ BAS scale } & lower burden & 80 & $46-65$ & 51.86 & 5.87 & -18.60 & 0.00 \\
\cline { 2 - 5 } & higher burden & 74 & $66-104$ & 75.27 & 9.45 & \\
\hline
\end{tabular}

BAS - burden assessment schedule 
Table 5. Mean of caregiver burden on the various domains of Burden Assessment Schedule scale (spouse $n=83$, other caregiver $n=71$ )

\begin{tabular}{|c|c|c|c|c|c|c|}
\hline \multirow[t]{2}{*}{ Domains } & \multicolumn{2}{|c|}{ Spouse } & \multicolumn{2}{|c|}{ Others caregiver } & \multirow[t]{2}{*}{$t$ test } & \multirow[t]{2}{*}{$p$ value } \\
\hline & Mean & SD & Mean & SD & & \\
\hline Spouse-related & 7.37 & 1.31 & - & - & & \\
\hline Physical and mental health of caregiver & 10.01 & 3.63 & 11.63 & 3.83 & -2.69 & 0.37 \\
\hline External support & 11.08 & 2.13 & 11.08 & 1.39 & 0.00 & 0.38 \\
\hline Caregiver routine & 5.64 & 1.66 & 5.97 & 1.78 & -1.202 & 0.78 \\
\hline Support of patients & 6.81 & 2.15 & 7.73 & 2.36 & -2.54 & 0.25 \\
\hline Taking responsibility & 8.69 & 2.30 & 9.45 & 2.32 & -2.04 & 0.94 \\
\hline Other relationship & 2.32 & 0.68 & 2.52 & 0.71 & -1.74 & 0.06 \\
\hline Patient's behaviour & 5.35 & 1.72 & 5.96 & 1.89 & -2.09 & 0.24 \\
\hline Caregiver's strategy & 7.05 & 1.75 & 7.32 & 1.79 & -0.96 & 0.87 \\
\hline Total & 64.34 & 13.96 & 61.68 & 14.17 & 1.17 & 0.77 \\
\hline
\end{tabular}

Table 6. Association of different demographic profiles with spouse-related domain of Burden Assessment Schedule scale

\begin{tabular}{|c|c|c|c|c|c|}
\hline Variables & Groups & Mean & SD & $f / t$ value & Sig. \\
\hline \multirow[t]{2}{*}{ Age } & $50(n=67)$ & 5.22 & 0.57 & 0.07 & 0.79 \\
\hline & $50+(n=16)$ & 5.87 & 0.62 & & \\
\hline \multirow[t]{2}{*}{ Sex } & male $(n=44)$ & 5.09 & 0.56 & 4.08 & 0.04 \\
\hline & female $(n=39)$ & 5.64 & 0.58 & & \\
\hline \multirow[t]{2}{*}{ Education } & illiterate $(n=26)$ & 4.85 & 0.46 & 12.85 & 0.01 \\
\hline & literate $(n=57)$ & 5.58 & 0.56 & & \\
\hline
\end{tabular}

Table 7. Association of caregiver burden (total Burden Assessment Schedule score) with demographic variables (spouse $n=83$, other caregiver $n=71$ )

\begin{tabular}{|c|c|c|c|c|c|}
\hline Variables & Groups & Mean & SD & $f / t$ value & Sig. \\
\hline \multirow[t]{2}{*}{ Age } & 50 & 60.56 & 13.48 & \multirow[t]{2}{*}{0.03} & \multirow[t]{2}{*}{0.86} \\
\hline & $50+$ & 67.10 & 14.17 & & \\
\hline \multirow[t]{2}{*}{ Sex } & male & 65.32 & 13.80 & \multirow[t]{2}{*}{-2.09} & \multirow[t]{2}{*}{0.03} \\
\hline & female & 70.25 & 14.81 & & \\
\hline \multirow[t]{2}{*}{ Education } & illiterate & 64.37 & 15.38 & \multirow[t]{2}{*}{1.16} & \multirow[t]{2}{*}{0.28} \\
\hline & literate & 62.57 & 13.52 & & \\
\hline \multirow[t]{2}{*}{ Relationship } & spouse & 64.34 & 13.96 & \multirow[t]{2}{*}{0.08} & \multirow[t]{2}{*}{0.77} \\
\hline & non spouse & 61.68 & 14.17 & & \\
\hline \multirow{3}{*}{$\begin{array}{l}\text { Caregiver's } \\
\text { occupation }\end{array}$} & unemployed & 64.78 & 14.93 & \multirow[t]{3}{*}{0.75} & \multirow[t]{3}{*}{0.47} \\
\hline & employed & 66.61 & 13.71 & & \\
\hline & house work & 69.28 & 15.53 & & \\
\hline \multirow{3}{*}{$\begin{array}{l}\text { Patient's occu- } \\
\text { pation }\end{array}$} & unemployed & 72.47 & 16.36 & \multirow[t]{3}{*}{2.20} & \multirow[t]{3}{*}{0.11} \\
\hline & employed & 67.21 & 14.28 & & \\
\hline & house work & 64.98 & 13.17 & & \\
\hline
\end{tabular}


age group more than 50 years perceived more burden than other age groups.

Correlations of caregiver burden (total BAS score) with different parameters - IDEAS score and its inter-domains, PANSS, caregiver's age, patient's age, duration of illness (Table 8).

In our study, the correlation between total BAS score and total IDEAS score and the following inter-domains of IDEAS - interpersonal, communication and employment - is highly significant. Deficit in all these domains affects burden of care in caregivers. Burden of care in the caregiver increases with increasing disability in the patient. There is a significant correlation between total BAS score and PANSS score as the $p$ value of 0.00 is significant. As psychopathology (PANSS score) increases, burden of care also increases. There is no significant correlation between total BAS score and different parameters - caregiver's age, duration of illness and patient's age.

\section{Discussion}

This study primarily aimed to study the nature of disability and caregiver burden in stable schizophrenia patients. In our study, the relation of different demographic factors with total BAS score shows that sex had an effect on burden of care associated with caregivers, with the $p$ value (0.03) being statistically significant. Burden of care increases with increasing age of caregivers and female caregivers perceived more burden than male caregivers. Others parameters - education, caregiver's and patient's occupation - had no correlation with total BAS score, as the $p$ value is not statistically significant $(>0.05)$.

In this study, greater burden of care was experienced with increasing age. A previous study demonstrated that advancing age of family member was an important predictor of burden (Kumar et al. 2015; Rammohan et al. 2002). Another study by Sharma (2014) concluded that burden increased with age and a lower burden existed at 36-45 years of age than the other age groups. As age increases, an individual is challenged by various stressors e.g., age-related health issues, financial issues, poor social support, decreased mental and physical ability. Graduate caregivers perceived more burden than the illiterates. A previous study by Sharma (2014) on caregivers who were educated between class $\mathrm{VI}$ and $\mathrm{X}$ showed less burden than primary level educated caregivers. This is possibly because of the different settings in which the study was
Table 8. Correlations of caregiver burden (total Burden Assessment Schedule score) with different parameters - Indian Disability Evaluation and Assessment Scale score and its inter-domains, Positive and Negative Syndrome Scale, caregiver's age, patient's age, duration of illness

\begin{tabular}{lcc} 
Variables & $\begin{array}{c}\text { Pearson } \\
\text { correlation }\end{array}$ & Sig. (2-tailed) \\
Caregiver's age & -0.15 & 0.06 \\
\hline Patient's age & 0.09 & 0.22 \\
\hline Duration of illness & -0.06 & 0.43 \\
\hline PANSS score & 0.55 & 0.00 \\
\hline IDEAS score & 0.44 & 0.00 \\
\hline Self-care & 0.14 & 0.07 \\
\hline Interpersonal & 0.28 & 0.00 \\
\hline Communication & 0.41 & 0.00 \\
\hline Employment & 0.51 & 0.00 \\
\hline
\end{tabular}

conducted. Both females and wives as caregivers tended to perceive more burden when compared to male caregivers. This is consistent with the findings of Kumar and Mohanty (2007) and Sharma et al. (2014) where wives and females as caregivers experienced more burden than husbands and males as caregivers respectively. In our study, spouse caregivers experienced more burden than other caregivers. Sharma (2014) demonstrated that severe burden was experienced if caregivers were spouses. In the Indian social context the female spouse has a dual role of managing household work as well as an income producer.

In our study, there is a significant correlation between total BAS score, total IDEAS score, and the interpersonal, communication and employment inter-domains of IDEAS as highly statistically significant, meaning the higher the disability is, the higher is the burden. Deficit in all these domains increases burden of care in caregivers. There is a significant correlation between total BAS score and PANSS score, as the $p$ value is highly significant. As psychopathology (PANSS score) increases, burden of care also increases. The Kumar et al. (2015) study in South India found that the correlations between total BAS score and PANSS score, IDEAS score, age of the caregiver, gender of the patient and duration of treatment were significant, while age of the patient and duration of illness did not have a significant correlation with burden scores. A study in India by Arun et al. (2018) demonstrated that the most powerful determi- 
nant of spousal caregiver burden was the degree of disability as measured by IDEAS.

In conclusion, two thirds of schizophrenia patients who were stable on medication for at least 6 months and diagnosed with schizophrenia for at least 2 years had mild $(70.1 \%)$ disability and the rest had moderate disability (29.9\%). Unemployed patients (mean IDEAS score of $7.0 \pm 2.6)$ had more disability than employed patients (mean IDEAS score of $4.8 \pm 2.2$ ). Patients of the age group 41-50 years had more disability than younger age groups. Patient's family status and education have no effect on disability of the person. Caregivers and patients themselves with higher secondary and graduate education and patients of lower middle socioeconomic class III reported more deficiency in the self-care domain, probably because of higher achieved and expected self-care levels. Interpersonal activities were more affected in unemployed (mean IDEAS score of 0.61) and household working patients (mean IDEAS score of 0.52 ) than employed patients (mean IDEAS score of 0.25 ).

In spouse caregivers, burden increases with increasing age. Female spouse caregivers (mean BAS score of $7.8 \pm 1.4$ ) perceived higher burden than male spouse (mean BAS score of $7.1 \pm 1.2$ ). Younger age group caregivers perceived more burden than older age group caregivers in giving financial and family support to the patient. Females, mainly wives (mean BAS score of 8.1 \pm 1.3 ), perceived more burden than parents of patients (mean BAS score of $7.5 \pm 1.2$ ) in maintaining the family relationship. All caregivers perceived a high level of burden in the areas of external support, support of patient, other relationships and patient's behaviour related area.

Strengths of the study include the following. First, it was done exclusively on a hospital-based day-to-day outpatient sample. Second, this study was done on a stable population with the disease. Third, standardized scales were used and were administered by a single person here by eliminating inter-rater bias. Limitations of the study are that it was a cross-sectional study, follow-up of the patients was not done and the sample size was small. A control group was not taken; hence no comparison was possible. Children and geriatric schizophrenia patients were not included in the study.

There is a need for long-term treatment and follow-up as much as improvements in community-based family intervention programs delivered by mental health services. These factors can be considered in future research in this area. Patients treated at the community level are associated with lesser disability (Thirthalli et al. 2010). These benefits can be maintained over extended periods of time (Thirthalli et al. 2009).

In summary, patients were stable on medication for at least 6 months, with good family support, maintaining treatment for longer duration, with no treatment default, no poor compliance, no acute episode and no institutionalization, showed mild to moderate disability, and there was a lower burden of care in caregivers (Thirthalli et al. 2010). Caregivers' burden has a direct correlation with overall disability. Deficiency in interaction, communication and employment leads to more burden of care, but not a deficiency in self-care (Thirthalli et al. 2009).

\section{References}

1. Arun R, Inbakamal S, Tharyan A, et al. Spousal caregiver burden and its relation with disability in schizophrenia. Indian J Psychol Med 2018; 40: 22-28.

2. Caqueo-Urízar A, Gutierrez-Maldonado J, Miranda-Castillo C. Quality of life in caregivers of patients with schizophrenia: a literature review. Health Qual Life Outcomes 2009; 7: 84 .

3. Chandrashekar H, Naveen Kumar C, Prashanth NR, et al. Disabilities research in India. Indian J Psychiatry 2010; 52: S281-S285.

4. Chang SM, Cho SJ, Jeon HJ, et al. Economic burden of schizophrenia in South Korea. J Korean Med Sci 2008; 23: 167-175.

5. Cloutier M, Aigbogun MS, Guerin A, et al. The economic burden of schizophrenia in the United States in 2013. J Clin Psychiatry 2016; 77: 764-771.

6. Flyckt L, Löthman A, Jörgensen L, et al. Burden of informal care giving to patients with psychoses: a descriptive and methodological study. Int J Soc Psychiatry 2013; 59: 137-146.

7. Greenberg JS, Greenly JR, McKean D, et al. Mothers caring for an adult child with schizophrenia: the effect of burden on maternal health. Fam Rel 1993; 42: 205-211.

8. Kay SR, Fiszbein A, Opler LA. The positive and negative syndrome scale (PANSS) for schizophrenia. Schizophr Bull 1987; 13: 261-276.

9. Kuipers L. Family burden in schizophrenia: implications for services. Soc Psychiatry Epidemiol 1993; 28: 207-210.

10. Kumar CN, Suresha KK, Thirthalli J, et al. Caregiver burden is associated with disability in schizophrenia: results of a study from a rural setting of south India. Int I Soc Psychiatry 2015; 61: 157-163.

11. Kumar S, Mohanty S. Spousal burden of care in schizophrenia. J Indian Acad Appl Psychol 2007; 33: 189-194.

12. Kung WW. The illness, stigma, culture, or immigration? Burdens on Chinese American caregivers of patients with schizophrenia. Fam Society 2003; 84: 547-557.

13. Marcellusi A, Fabiano G, Viti R, et al. Economic burden of schizophrenia in Italy: a probabilistic cost of illness analysis. BMJ Open 2018; 8: e018359.

14. Martyns-Yellowe IS. The burden of schizophrenia on the family. A study from Nigeria. Br J Psychiatry 1992; 161: 779-782. 
15. Ong HC, Ibrahim N, Wahab S. Psychological distress, perceived stigma, and coping among caregivers of patients with schizophrenia. Psychol Res Behav Manag 2016; 9: 211-218.

16. Rammohan A, Rao K, Subbakrishna DK. Burden and coping in caregivers of persons with schizophrenia. Indian J Psychiatry 2002; 44: 220-227.

17. Rehabilitation Committee of the Indian Psychiatric Society. Indian disability evaluation and assessment scale (IDEAS): a scale for measuring and quantifying disability in mental disorders, Indian Psychiatric Society 2002.

18. Sharma PK. Burden in care of patients with schizophrenia: to which extent caregiver suffers. J Pharm Scilnnov 2014; 3: 522-552.

19. Tamminga CA. Schizophrenia and other psychotic disorders - introduction and overview. In: Kaplan \& Sadock's Comprehensive Textbook of Psychiatry. $9^{\text {th }}$ ed. Sadock BJ (Ed.). Lippincott Williams \& Wilkins; Philadelphia 2009; 1432.

20. Thara R, Padmavati R, Kumar S, et al. Instrument to assess burden on caregivers of chronic mentally ill. Indian J Psychiatry 1998; 40: 21-29.

21. Thirthalli J, Venkatesh BK, Kishorekumar KV, et al. Prospective comparison of course of disability in antipsychotic-treated and untreated schizophrenia patients. Acta Psychiatr Scand 2009; 119: 209-217.

22. Thirthalli J, Venkatesh B, Naveen $M$, et al. Do antipsychotics limit disability in schizophrenia? A naturalistic comparative study in the community. Indian J Psychiatry 2010; 52: 37-41.

23. Tsang HW, Tam PK, Chan F, et al. Sources of burdens on families of individuals with mental illness. Int J Rehabil Res 2003; 26: 249.

24. Vermeulen B, Lauwers $\mathrm{H}$, Spruytte $\mathrm{N}$, et al. Experiences of family caregivers for persons with severe mental illness: an international exploration. Eur Neuropsychopharmacol 2015; 25: S374.

25. WHO Centre for Health Development. A glossary of terms for community health care and services for older persons. Kobe, Japan: WHO Centre for Health Development, 2004. https://apps.who.int/iris/handle/10665/68896.

26. World Health Organization. International classification of diseases, diagnostic classification for research. Geneva, Switzerland 1992. 